\title{
REVIEW
}

\section{Neonatal tachycardias: an update}

\author{
D S Kothari, J R Skinner
}

Arch Dis Child Fetal Neonatal Ed 2006;91:F136-F144. doi: 10.1136/adc.2004.049049

This review provides an updated framework for the diagnosis and management of neonatal tachycardias.

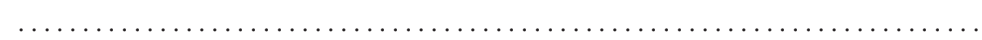

T he most commonly presenting pathological tachycardia in the newborn is a narrow complex supraventricular tachycardia (SVT). In an infant without obvious circulatory compromise, identification of the tachycardia and its management with either facial immersion in cold water or rapid injection of intravenous adenosine is uncontroversial. ${ }^{1}$ However, management of the infant with circulatory compromise, or with a history of fetal hydrops, antenatal polypharmacy, prematurity, or congenital heart disease is more difficult. There is a risk of death from the underlying problem or due to inappropriate or inadequate treatment, and an understanding of the mechanisms of tachycardias is important to make a logical management plan.

This review aims to provide the neonatologist with an updated framework for the diagnosis and management of neonatal tachycardias.

\section{MECHANISMS OF TACHYCARDIA}

Figure 1 shows the various mechanisms of tachycardia.

The term supraventricular tachycardia or SVT is a bad one. When an accessory pathway is involved in the most common form of neonatal SVT, the re-entry circuit starts in the atrium, passes through the specific conduction system, much of the ventricle, the accessory pathway, and then back to the atrium. Clearly this is a "whole heart" tachycardia and not just above the ventricles. The only tachycardias that are truly supraventricular are atrial tachycardias, such as atrial flutter, which do not depend on either the specific conduction tissue or the ventricles for them to be sustained.

To understand the mechanism of tachycardias, it is thus helpful to consider the heart in three levels: the atria, the conduction system, and the ventricles. The atria and ventricles are electrically isolated from each other, other than via the specific conduction system.

See end of article for authors' affiliations .....................

Correspondence to: Dr Skinner, Department of Cardiology, Green Lane Hospital, Green Lane West, Auckland 3, New Zealand; jskinner@adhb. govt.nz

Accepted 2 August 2005

.................... from the atria to the ventricles in a manner that (a) delays the impulse to allow ventricular filling and $(b)$, after a period of delay, transmits this impulse rapidly through the ventricles, to allow coordinated ventricular contraction.
The delay provided by the AV node also provides protection in the event of atrial tachycardias. Atrial fibrillation, for example, would cause ventricular fibrillation if the AV node did not have a programmed delay within it. The haemodynamic status of a fetus or infant with atrial flutter depends critically on the block provided by the AV node. Increasing this delay, with $\beta$ blockers or digoxin for example, can helpfully reduce the ventricular rate until the atrial flutter ceases.

\section{ATRIAL TACHYCARDIAS}

Atrial tachycardias often occur in neonates, and they have certain features in common. As the atrium is depolarised in an abnormal manner, the $\mathrm{P}$ wave has a different shape and/or axis from sinus rhythm. With all forms, the relation of the $\mathrm{P}$ wave to the QRS complex may be variable, depending on AV nodal conduction, and the ventricular rate can be somewhat irregular if there is variable AV block. Management can usefully be directed at either stopping the tachycardia or slowing the ventricular rate by reducing AV node conduction.

\section{Atrial flutter}

Common in the fetus and the newborn, it becomes very rare again until adult life. The mechanism in the newborn is presumed to be the same as in the older patient where it is known to be a re-entry mechanism with a critical zone of conduction between the inferior vena cava and the tricuspid valve. Once cardioverted into sinus rhythm, it rarely recurs, although some may suffer accessory pathway mediated SVT in later life.

Atrial flutter can be well tolerated, even asymptomatic, if there is a high degree of $\mathrm{AV}$ node block and the ventricular rate is near normal. If AV nodal conduction is brisk, $1: 1 \mathrm{AV}$ conduction can occur, and, as atrial flutter is usually at the rate of more than 300 beats/min, this inevitably leads to circulatory compromise or death. It is an important cause of fetal hydrops.

In managing atrial flutter and other rapid atrial tachycardias, it is dangerous to reduce the rate of the flutter pharmacologically in the atria without simultaneously blocking the AV node. Some drugs, most notably flecainide, can do this. The ventricular rate can suddenly and fatally increase when the atrial rate reduces to the point when the AV node, instead of blocking every second beat (2:1 AV block), now conducts every beat ( $1: 1$ AV conduction). The ventricular rate suddenly doubles, with disastrous consequences.
Abbreviations: $A V$, atrioventricular; $D C$, direct current; ECG, electrocardiogram; SVT, supraventricular tachycardia; VT, ventricular tachycardia 


\begin{tabular}{|c|c|c|}
\hline Ectopic atrial tachycardia & $\begin{array}{l}\text { - Abnormal P wave axis. } \\
\text { P Pave precedes QRS. } \\
\text { - Variable rate. } \\
\text { - Warm up" and "cool down" phenomenon. }\end{array}$ & $\begin{array}{l}\text { - May be incessant. } \\
\text { - May not respond to electrical } \\
\text { cardioversion or adenosine due to } \\
\text { "automatic" nature (see fext). } \\
\text { - Can lead to tachycardia induced } \\
\text { cardiomyopathy if uncontrolled. }\end{array}$ \\
\hline Atrial flutter & $\begin{array}{l}\text { - Atrial rate up to } 500 \text { beats/min in newborns. } \\
\text { - Sawtooth flutter waves. } \\
\text { - Variable AV conduction common. }\end{array}$ & $\begin{array}{l}\text { - Adenosine unmasks the atrial flutter by } \\
\text { causing AV block. } \\
\text { - Maintenance antiarrhythmics must result } \\
\text { in some AV nodal block. Avoid flecainide } \\
\text { or propafenone in isolation. }\end{array}$ \\
\hline $\begin{array}{l}\text { Multifocal atrial } \\
\text { tachycardia } \\
(1)=0\end{array}$ & $\begin{array}{l}\text { - Irregularly irregular. } \\
\text { - Multiple different } \mathrm{P} \text { wave morphologies } \\
\text { bizarre and chaotic. } \\
\text { - No two RR intervals the same. }\end{array}$ & $\begin{array}{l}\text { - Will not usually respond to DC } \\
\text { cardioversion or adenosine. } \\
\text { IV amiodarone usually effective. }\end{array}$ \\
\hline $\begin{array}{l}\text { Atrioventricular re-entry } \\
\text { tachycardia } \\
\text { Orthodromic } \\
\text { tachycardia: }\end{array}$ & $\begin{array}{l}\text { - P wave follows QRS, typically on } \\
\text { upstroke of } T \text { wave. }\end{array}$ & $\begin{array}{l}\text { - Commonest form of neonatal SVT. } \\
\text { - Adenosine sensitive. }\end{array}$ \\
\hline $\begin{array}{l}\text { Antidromic } \\
\text { tachycardia: }\end{array}$ & - Superior $\mathrm{P}$ wave axis (inverted in II and aVF). & $\begin{array}{l}\text { - Preexcitation (delta wave) and short PR } \\
\text { interval seen post termination in WPW. } \\
\text { - Adenosine sensitive. }\end{array}$ \\
\hline $\begin{array}{l}\text { Atrioventricular nodal } \\
\text { re-entry tachycardia }\end{array}$ & $\begin{array}{l}\text { - } P \text { wave usually not visible, superimposed } \\
\text { on QRS. }\end{array}$ & - Adenosine sensitive. \\
\hline $\begin{array}{l}\text { Permanent junctional } \\
\text { reciprocating tachycardia }\end{array}$ & $\begin{array}{l}\text { - Inverted P waves in II, III, aVF appear to } \\
\text { precede QRS complex. } \\
\text { - Adenosine transiently terminates tachycardia. }\end{array}$ & $\begin{array}{l}\text { - Incessant, slower rate than others - about } \\
200 \text { beats/min. } \\
\text { - Typically restarts after electrical } \\
\text { cardioversion or adenosine. } \\
\text { - Maintenance antiarrhythmics such as } \\
\text { flecainide always required. } \\
\text { - Early catheter ablation may be required. } \\
\text { - Can lead to tachycardia induced } \\
\text { cardiomyopathy if uncontrolled. }\end{array}$ \\
\hline Ventricular tachycardia & $\begin{array}{l}\text { - Rare in neonates. } \\
\text { - Wide QRS complex. } \\
\text { - } \text { wamplem may be dissociated from the QRS } \\
\text { - "Capture" or "fusion". }\end{array}$ & $\begin{array}{l}\text { - Broad complex QRS "always" treat as } \\
\text { VI unless proved otherwise. } \\
\text { - Not terminated by adenosine. }\end{array}$ \\
\hline Ventricular fibrillation & $\begin{array}{l}\text { - Rare in neonates. } \\
\text { - Chaotic, irregular rhythm. }\end{array}$ & $\begin{array}{l}\text { - Consider long QT syndrome or Brugada } \\
\text { syndrome. }\end{array}$ \\
\hline
\end{tabular}

Figure 1 Mechanisms of tachycardia. AV, Atrioventricular; IV, intravenous; SVT, supraventricular; WPW, Wolff-Parkinson-White syndrome. 


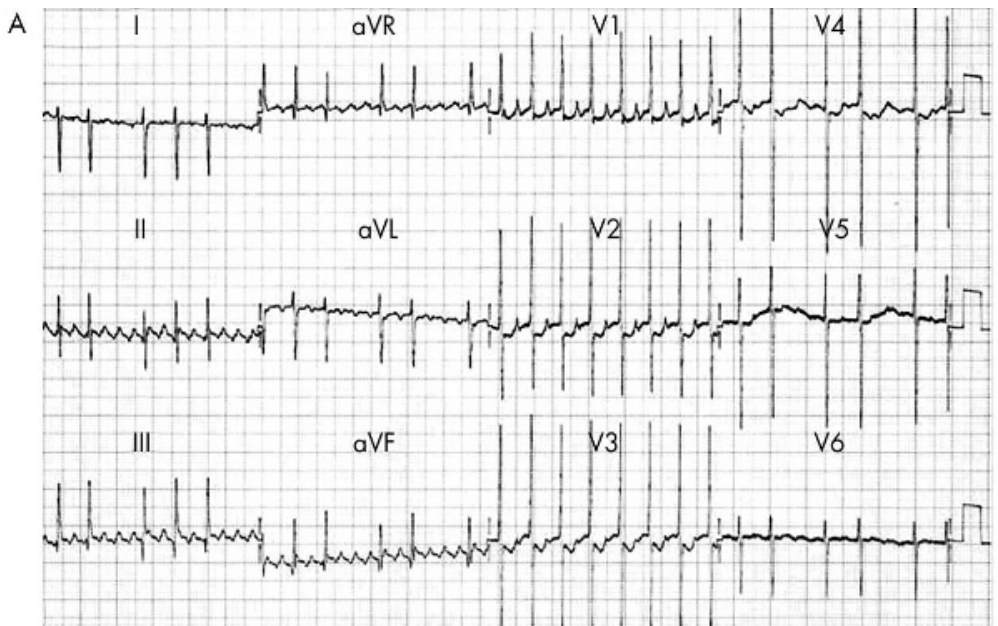

B

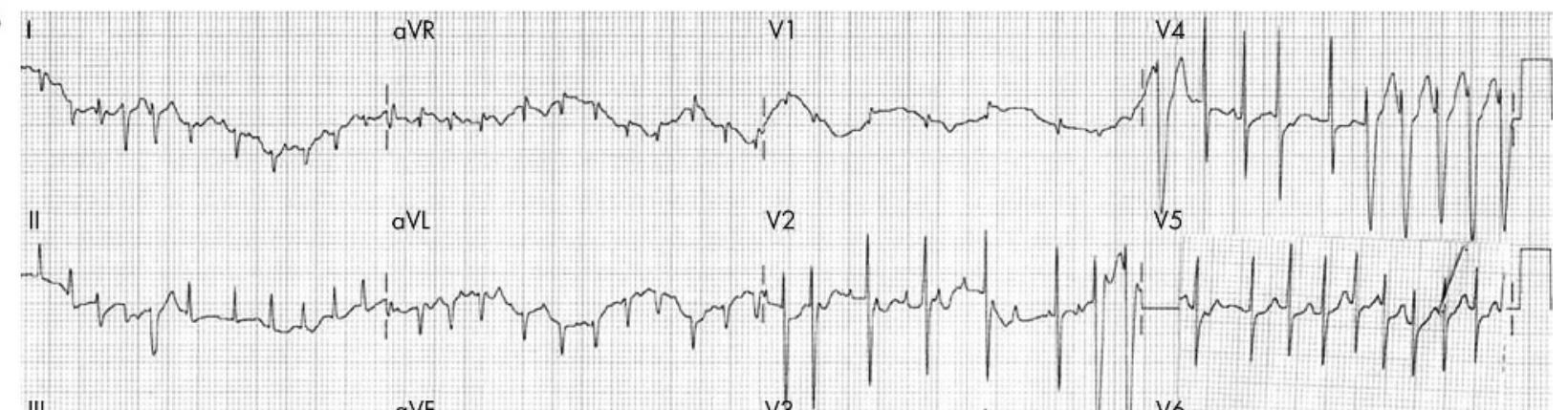

III $\quad$ aVF

V3

V6

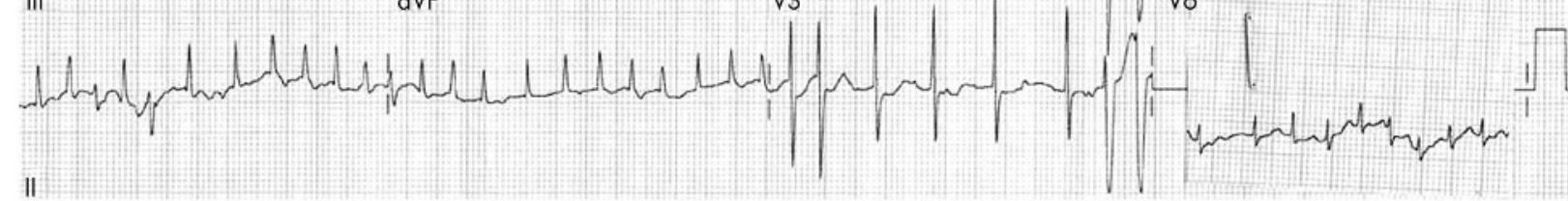

C

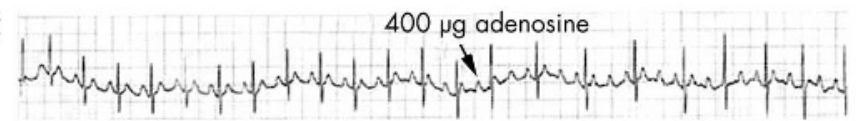

Figure 2 Atrial tachycardias. (A) 12 lead electrocardiogram during atrial flutter. The "saw tooth" P waves are seen most clearly in lead II, where there is a variable degree of AV block; there are two to four P waves for each QRS complex. The atrial rate is 350 beats $/ \mathrm{min}$. In leads V1-V3 there is regular 2:1 atrioventricular conduction so the ventricular rate is 175 beats $/ \mathrm{min}$. (B) Multifocal atrial tachycardia. The ventricular rate is rapid and irregular, and some of the QRS complexes are broad. The P waves are irregular, rapid, and have changing morphology; they are most clearly seen in V2, with two P waves for each QRS complex. At other times, the atrioventricular node conducts the impulse to the ventricles at a faster rate, seen best in V4. One of the bundles is refractory at this heart rate, leading to broader QRS complex. (C) Ectopic atrial tachycardia during administration of adenosine. In this case the diagnosis was uncertain, the $\mathrm{P}$ wave resembled a normal sinus $\mathrm{P}$ wave, and it was uncertain if the first deflection after the QRS complex was in fact a T wave. Adenosine increased the degree of atrioventricular block from 2:1 to 3:1, demonstrating that the deflections were all $P$ waves, and that the tachycardia did not depend on a re-entry circuit involving the specific conduction system. The atrial tachycardia stops also for one beat (around the fourth QRS complex from the end of the strip). This is occasionally seen with an ectopic atrial tachycardia, but not in atrial flutter. I-III, Bipolar leads; $\mathrm{aVF}$, aVL, and aVR, augmented voltage of the left foot, left arm, and right arm respectively; V1-V6, precordial leads.

Flecainide for atrial flutter should always be used with additional AV blocking agents, such as digoxin or $\beta$ blockers.

Differentiation from other SVTs is therefore important. Figure $2 \mathrm{~A}$ is an electrocardiogram (ECG) showing atrial flutter. Two or more P waves are seen for each QRS complex giving a variable ventricular rate. In cases with a regular ventricular rhythm, the diagnosis can be confirmed by giving adenosine, which, by blocking AV nodal conduction, reveals more atrial beats per QRS complex (fig 2C). In urgent situations it will respond to direct current (DC) cardioversion, intravenous amiodarone, or transoesophageal overdrive pacing. ${ }^{2}$ Long term medical prophylaxis is usually not necessary thereafter. ${ }^{3}$

\section{Ectopic atrial tachycardias}

These are manifested as narrow complex tachycardias with an abnormal P wave preceding the QRS complex.

\section{Atrial ectopy}

Atrial ectopy is very common in the fetus and neonate. The $\mathrm{P}$ wave can have varied morphology (the so called "wandering atrial pacemaker") or be from a single abnormal focus. These usually settle with time, and, provided that they do not result in a major tachycardia, reassurance is all that is required. Neither DC cardioversion nor adenosine work. Antiarrhythmic drugs are required for significant tachycardia.

\section{Multifocal atrial tachycardias}

These do occasionally produce cardiac compromise, and the ECG appearance and behaviour resembles atrial fibrillation (fig 2B). This term infant responded well to oral sotalol.

\section{Monomorphic ectopic atrial tachycardias}

These have a single abnormal $\mathrm{P}$ wave preceding each QRS complex. They tend to accelerate ("warm up") and decelerate or 
A

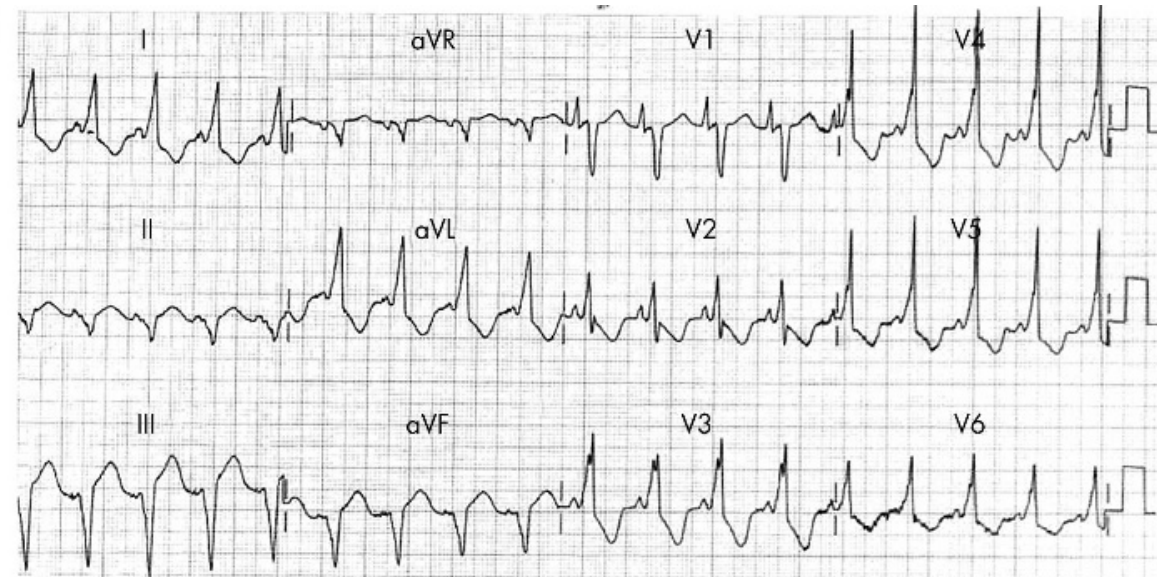

B

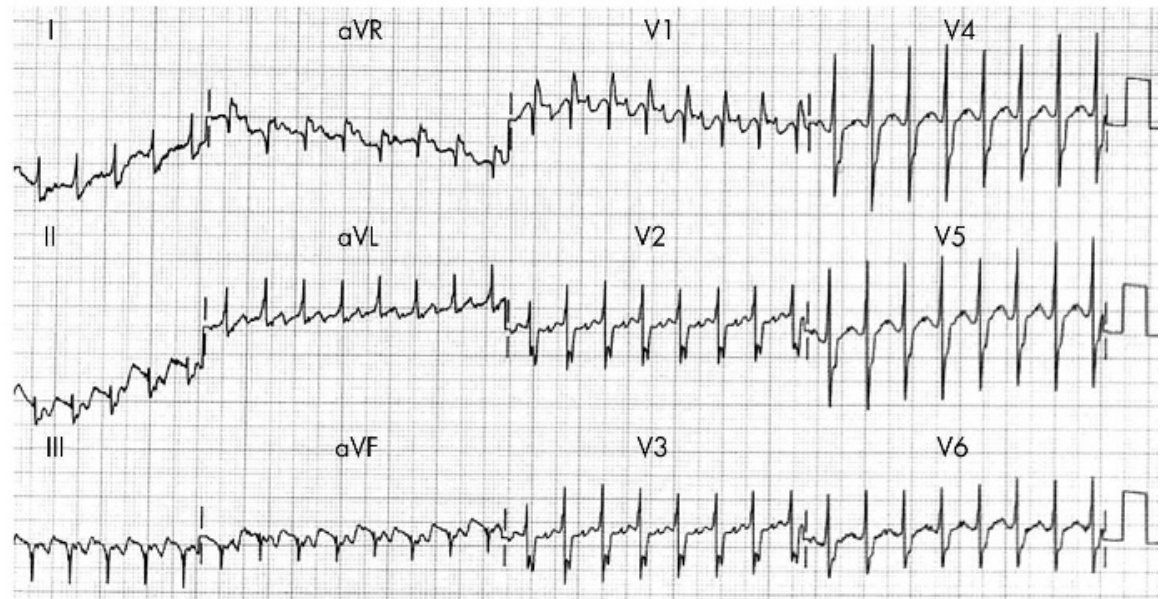

C

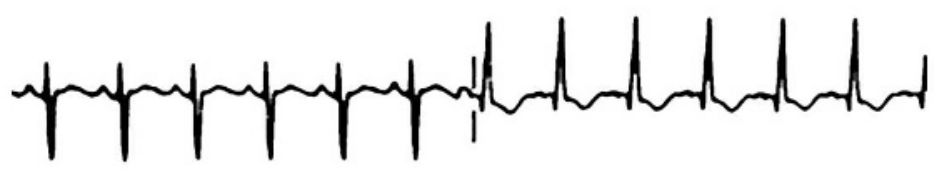

॥

$\mathrm{aVL}$

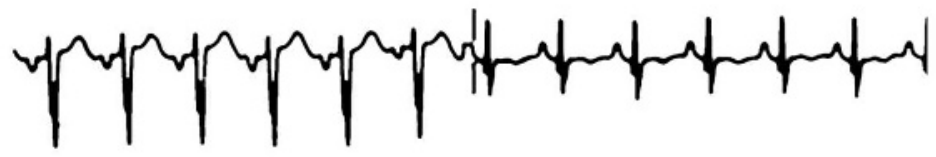

III

aVF

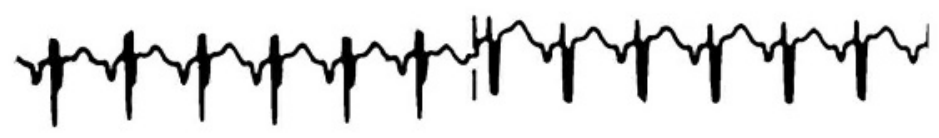

Figure 3 Accessory pathway mediated tachycardias. (A) 12 lead electrocardiogram (ECG). This infant had Wolff-Parkinson-White syndrome with Ebstein's anomaly of the tricuspid valve. The right atrial enlargement is evident from the tall P waves in lead V1. The pre-excitation is obvious in most of the leads, with a very short P-R interval. (B) 12 lead ECG during orthodromic atrioventricular re-entry tachycardia in the same patient as in fig 2A. The QRS complex is narrow, and the retrograde $\mathrm{P}$ wave, shortly after the QRS complex, is most obvious in leads V1 and aVL. (C) Permanent junctional reciprocating tachycardia. This 6 lead ECG shows the typical appearance of this tachycardia. The P waves in II and III are inverted, and are long after the QRS complex. This appearance can also be seen with an ectopic atrial tachycardia arising from low down in the atria. I-III, Bipolar leads; aVF, aVL, and aVR, augmented voltage of the left foot, left arm, and right arm respectively; V1-V6, precordial leads.

stop periodically ("cool down"), but they tend to be incessant at rates around 180-200 beats/min such that they may not present with overt paroxysms of tachycardia, but rather with gradual onset cardiac failure and even dilated cardiomyopathy.

\section{CONDUCTION SYSTEM TACHYCARDIAS}

There are two common types: atrioventricular re-entry tachycardia, mediated by an accessory pathway and AV nodal re-entry tachycardia. Both cause rapid and regular 


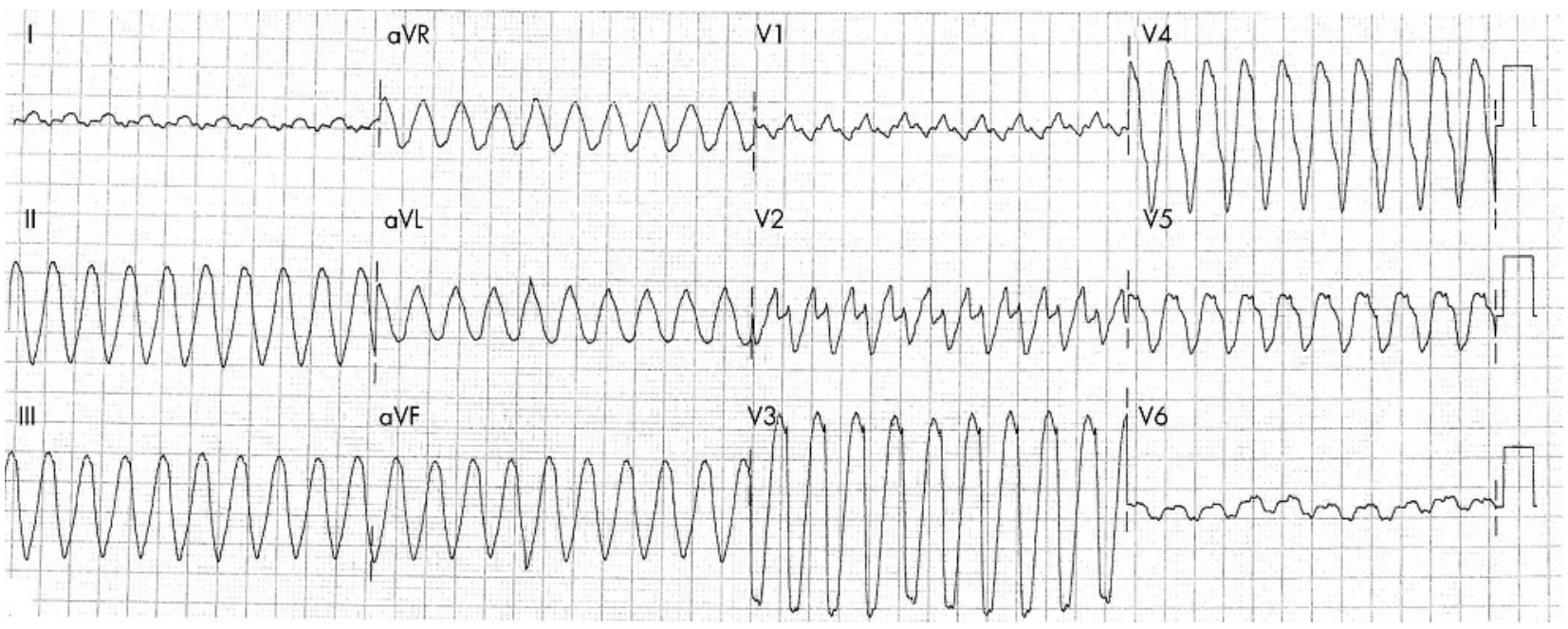

Figure 4 Electrocardiogram diagnosis of ventricular tachycardia showing a broad QRS complex. I-III, Bipolar leads; aVF, aVL, and aVR, augmented voltage of the left foot, left arm, and right arm respectively; V1-V6, precordial leads.

tachycardia responsive to adenosine, vagal manoeuvres, or DC cardioversion.

Two rare tachycardias, which will not be discussed further, are:

(1) junctional ectopic tachycardia, which is very rare outside the paediatric cardiac intensive care unit, where cooling and amiodarone are used in treatment;

(2) fascicular ventricular tachycardia (VT), which occurs outside the neonatal period with paroxysms of right bundle branch block, superior QRS axis tachycardia, typically unresponsive to adenosine, but responding to verapamil.

\section{Accessory pathways \\ Wolff-Parkinson-White syndrome}

In Wolff-Parkinson-White syndrome (fig 3A), electric signals can be conducted forwards and backwards through the pathway. The forward conduction is manifested by the delta wave at rest. The usual tachycardia circuit is down the AV node and up the accessory pathway, the so called "orthodromic" atrioventricular re-entry tachycardia (fig 3B). The QRS complex is narrow, as the ventricle is depolarised via the specific conduction system. A retrograde $\mathrm{P}$ wave is seen after the QRS complex, because it takes some time for the signal to pass through the ventricle and back up the accessory pathway.

Much less common is "antidromic" tachycardia, with forwards conduction down the accessory pathway, leading to a very broad QRS complex, the onset of which resembles an exaggerated delta wave. The electric impulse returns to the atria backwards up the specific conduction system.

As such accessory pathways can sometimes have a very short refractory period, they can conduct at very fast heart rates. In older children, death can occur from a paroxysm of atrial flutter or fibrillation being conducted directly into the ventricle. ${ }^{4}$ One study showed that the mean age of the first atrial fibrillation episode was 36 (16) years. ${ }^{5}$ This is not, however, documented to be a problem in neonates.

\section{Concealed accessory pathways}

Most accessory pathways are "concealed", there being no delta wave in sinus rhythm as there is no forwards conduction down these pathways. Such pathways can only mediate orthodromic re-entry, the commonest type of infant SVT.

Permanent junctional reciprocating tachycardia This uncommon tachycardia (fig 3C) is worthy of mention because it can be incessant at a relatively slow rate (around 200 beats/min) and is a treatable cause of dilated cardiomyopathy presenting in the neonate. It is mediated by a concealed, backwards conducting accessory pathway with slow, AV node-like conduction properties. The $\mathrm{P}$ wave is hence long after the QRS complex during tachycardia and is inverted in the inferior leads. The $\mathrm{P}$ wave is so far from the QRS complex it follows that it is closer to the next one, such that it is easily mistaken for an ectopic atrial tachycardia.

Treatment is difficult because response to adenosine or electrical cardioversion is transient, and long term medication, such as flecainide, is usually required. Fortunately, catheter ablation is relatively straightforward and can be considered at a young age.

\section{AV nodal re-entry tachycardias}

Much more common in adults and older children, AV nodal re-entry tachycardia is the result of so called "dual AV nodal physiology". A slow and fast pathway co-exist, and during tachycardia the circuit usually passes down the slow pathway and up the fast. The atria and ventricle are depolarised simultaneously, so the $\mathrm{P}$ wave is not visible, but "buried" within the QRS complex. It responds well to adenosine or facial immersion. Management is thus, in the immediate and long term medical treatment, no different from that of a concealed accessory pathway.

\section{VENTRICULAR TACHYCARDIA}

VT is extraordinarily rare in the neonate, even after cardiac surgery. Rapid polymorphic VT or ventricular fibrillation may occur with cardiac channelopathies, such as long QT and Brugada syndromes, and usually present with cardiac arrest and not a sustained conscious tachycardia. ${ }^{6}$ Sustained, conscious VT can occur, however, in the setting of birth asphyxia or with a rare cardiac tumour such as a hamartoma. $^{7}$

For an ECG diagnosis of VT, a broad QRS complex (usually over 120 milliseconds) must be present (fig 4). Diagnosis can be made with certainty if dissociation from atrial activity can be demonstrated. If an infant has rapid retrograde 


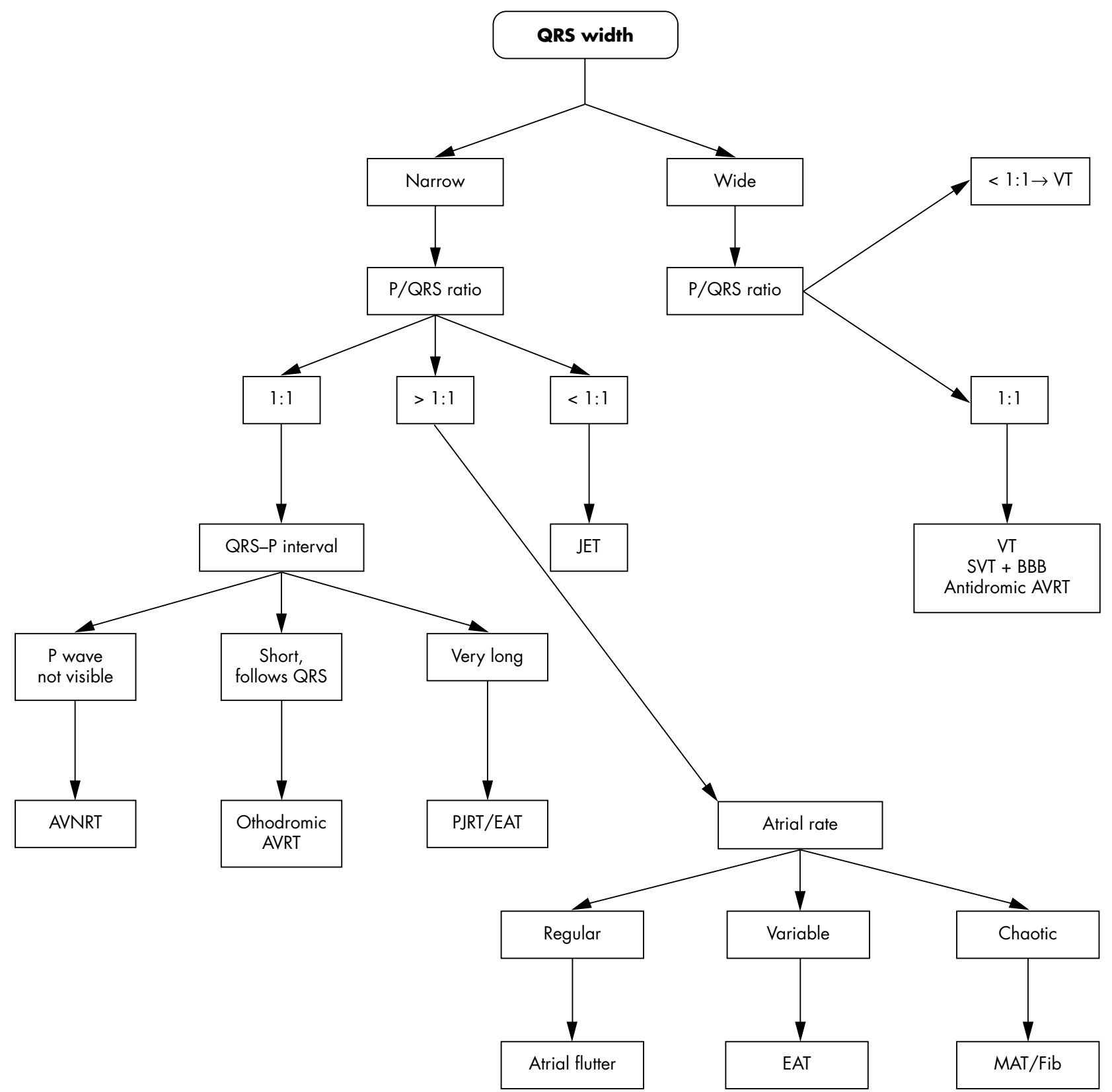

Figure 5 Algorithm for identifying tachycardias. VT, Ventricular tachycardia; JET, junctional ectopic tachycardia; SVT, supraventricular tachycardia; $\mathrm{BBB}$, bundle branch block; AVRT, atrioventricular re-entry tachycardia; AVNRT, atrioventricular nodal re-entry tachycardia; PJRT, permanent junctional reciprocating tachycardia; EAT, ectopic atrial tachycardia; MAT, multifocal atrial tachycardia; Fib, fibrillation.

conduction up the AV node, there will be 1:1 ventriculoatrial conduction, and it may be difficult in such cases to be certain this is not a re-entry SVT. If the infant is haemodynamically stable, it is reasonable to see if adenosine will cause cardioversion, thereby making a diagnosis of a conduction system dependent SVT.

So how can dissociation of atrial activity from ventricular activity be demonstrated on the ECG? The first feature is the identification of $\mathrm{P}$ waves running at a slower rate than the ventricle. The P waves alter the shape of the QRS complex by producing small notches in them. Secondly, occasionally a sinus beat will pass through the AV node and "capture" the bulk of the ventricle. This will lead to an isolated narrow complex beat known as a "capture" beat. This is pathognomonic of VT. A "fusion" beat is a mixture of a capture beat and a tachycardia beat. The broad complex tachycardia continues to run after a fusion or capture beat has occurred.
The differential diagnosis in broad complex tachycardia includes:

- VT

- SVT with a bundle branch block (usually right bundle branch block)

- Conduction forwards via an accessory pathway in WolffParkinson-White syndrome (antidromic re-entry or with atrial tachycardia)

\section{IDENTIFICATION OF TACHYCARDIAS}

A process for analysing the ECG and asking for advice To diagnose the problem and also to communicate it to a colleague by phone, it is imperative to have a system. An easy sequence is (a) QRS complex rate, regularity, and width followed by $(b)$ the relation of the $\mathrm{P}$ wave to the QRS 
Table 1 Classification of pharmaceutical agents used in the management of neonatal tachycardias

\begin{tabular}{ll}
\hline Classification & Drugs \\
\hline Class 1: sodium channel blockers & Flecainide, propafenone \\
Class 2: $\beta$ blockers & $\begin{array}{l}\text { Atenolol, propranolol, esmolol, } \\
\text { nadolol }\end{array}$ \\
Class 3: potassium channel blockers & $\begin{array}{l}\text { Amiodarone, sotolol ( }+\beta \text { blocker } \\
\text { effect) }\end{array}$ \\
Class 4: calcium channel blockers & Verapamil, diltiazem \\
\hline
\end{tabular}

complex, and the $\mathrm{P}$ wave morphology. Figure 5 shows an algorithm to guide this process. This is modified from that described in a very useful text by Walsh et al. ${ }^{8}$ The rate itself gives some clues. In the neonate, SVT is usually faster than 220 beats/min, and in the preterm infant or fetus the rate is usually over 250 beats/min. Re-entry tachycardias, such as those mediated by an accessory pathway, tend to be extremely regular with a fixed rate, whereas sinus tachycardia fluctuates. Ectopic atrial tachycardias and permanent junctional reciprocating tachycardias have relatively minor rate fluctuations compared with sinus rhythm.

\section{Sending ECGs for review by a colleague}

Faxes can be a nightmare to interpret because of paper distortion, false noise, and poor definition. Sending a jpeg email of an ECG is much better. A flat bed scanner at a minimum resolution of $150 \mathrm{dpi}$ should be used.

\section{TREATMENT}

\section{Early management}

Initial management, based on the guidelines of the advanced paediatric life support group, depends on the general condition of the infant. Circulatory collapse with a tachycardia whether broad or narrow complex requires DC cardioversion, which should be synchronised, provided that the QRS complexes are reliably detected by the monitor. If the compromise is not critical, it is reasonable to try adenosine first. Vagal manoeuvres such as facial immersion are dangerous and inappropriate in this context.

In the infant with a narrow complex tachycardia who is not compromised, facial immersion can be used. With the infant wrapped in a towel and connected to an ECG, the face is immersed for approximately five seconds into a bowl of cold water. It is safe and effective. ${ }^{1}$ Ocular pressure is not recommended at any age, and carotid massage does not work and compresses the airway. If facial immersion fails, adenosine at an initial dose of $200 \mu \mathrm{g} / \mathrm{kg}$ can be given rapidly intravenously into a large vein (such as the antecubital fossa). Up to $500 \mu \mathrm{g} / \mathrm{kg}$ is occasionally required. ${ }^{9}$

Failure of adenosine to terminate the tachycardia may be due to:

(1) inadequate dosage or too slow administration of the drug

(2) the mechanism being atrial tachycardia; as adenosine blocks the AV node, it may reveal atrial flutter or atrial tachycardia as the cause of the problem (fig 2c)

(3) the mechanism being VT

Transient termination of a conduction system dependent tachycardia, with a few beats of sinus rhythm before restarting, is not uncommon. In this case, additional antiarrhythmic treatment is required.

Intravenous amiodarone is increasingly finding favour for this for a number of reasons.

(1) It will work if the diagnosis is SVT or VT.

(2) It has little negative inotropic effect, so it is relatively safe when myocardial function may be compromised.

(3) It is effective with atrial flutter and safer than intravenous flecainide because it slows AV nodal conduction as well as slowing and eventually interrupting the flutter circuit.

\section{Maintenance therapy}

Various pharmaceutical agents are used in the management of neonatal tachycardias.

The standard classification of commonly used drugs is the Vaughan Williams' classification of antiarrhythmics (table 1).

When considering maintenance therapy, there are three main questions to be answered.

\section{Who needs the treatment?}

The natural history of SVT presenting in the neonate suggests that spontaneous resolution usually occurs in the first year of life. ${ }^{111}$ For infants born with a history of fetal SVT, doctors choose to give maintenance antiarryhthmic therapy postnatally to $52-65 \%$ of non-hydropic fetuses and about $80 \%$ of hydropic fetuses. ${ }^{12}{ }^{13}$ It is our practice to give prophylactic antiarrhythmic therapy to most neonates presenting cardioverted from SVT except for well tolerated atrial flutter.

Table 2 Important drugs, their effect on the atrioventricular node, and other salient features

\begin{tabular}{|c|c|c|}
\hline Drug & Effect & Comments \\
\hline Amiodarone & Slows conduction & $\begin{array}{l}\text { - Long half life; many weeks or months may be required to achieve steady state } \\
\text { plasma amiodarone concentration. } \\
\text { - Liver function and thyroid-function tests required before treatment and then } \\
\text { every } 6 \text { months. } \\
\text { - Useful for VT and SVT that is not responsive to adenosine. }\end{array}$ \\
\hline Sotolol & Slows conduction to an extent & $\begin{array}{l}\text { - Pro-arrhythmic effects: bradycardia and prolongs the QT interval. } \\
\text { - Not to be used with verapamil. } \\
\text { - Useful in refractory SVT in combination with flecainide. }\end{array}$ \\
\hline Flecainide & Little effect on conduction & $\begin{array}{l}\text { - Pro-arrhythmic effects with toxicity. } \\
\text { - Monitor flecainide levels; danger in renal impairment } \\
\text { - Useful, alone or in combination with sotolol, for refractory SVT. }\end{array}$ \\
\hline Adenosine & Slows/blocks conduction & $\begin{array}{l}\text { - Rapid reversion to sinus rhythm. } \\
\text { - Aid to diagnosis of broad or narrow complex SVT } \\
\text { - Unmasks atrial flutter. }\end{array}$ \\
\hline Propafenone & Little effect on conduction & $\begin{array}{l}\text { - No concentration-effect relation in the therapeutic ranges, thus titration of } \\
\text { plasma concentrations is of little clinical significance in guiding treatment. }{ }^{14} \\
\text { - Prolongs QT interval. }\end{array}$ \\
\hline
\end{tabular}




\section{What drug to choose?}

Choice of antiarrhythmic drugs is based on the severity of the presentation, the mechanism of the tachycardia, in particular the presence/absence of delta wave, and other factors such as proximity to a hospital and a doctor's personal experience.

The Vaughan Williams' classification is of little practical use in choosing the right drug. It is more helpful to consider the drugs first in terms of their place of action in the heart, in particular $(a)$ do they block the AV node? $(b)$ do they slow conduction in an accessory pathway? Secondly, their potential side effects and need for monitoring need to be considered. Table 2 summarises some salient features of the most common drugs.

For a well tolerated, adenosine sensitive tachycardia that reverted easily, we would choose a long acting $\beta$ blocker. No specific monitoring is required, and $\beta$ blockers are extremely safe. For an infant who presented in shock, or in whom cardioversion was difficult, perhaps requiring intravenous amiodarone, we would choose a more powerful antiarryhthmic drug, such as sotalol, flecainide, or amiodarone, each requiring more intensive monitoring. Blood flecainide concentrations need to be measured about seven days into treatment to ensure that toxic concentrations are not reached; subtherapeutic blood concentrations are, however, often adequate in clinical practice. With sotalol, the QT interval must be monitored, and the dose adjusted if the heart rate corrected QT interval (QTC) approaches 0.50 second. Sotalol has some $\beta$ blocking effect, and should be introduced cautiously if there is myocardial dysfunction.

Digoxin is sometimes used as adjunctive treatment to provide some AV block in combination with another agent, particularly flecainide, but also sotalol and amiodarone. We do not use digoxin as a lone agent, as there is doubt that it is effective at all. It is extremely poisonous in overdose, and concentrations in the blood need to be monitored. Most doctors do not use digoxin in the presence of a delta wave, because of the potential risk of accelerating antegrade accessory pathway conduction in the event of an atrial tachycardia.

\section{How long to continue?}

Most (60-90\%) infants with Wolff-Parkinson-White syndrome undergo spontaneous resolution by 1 year of age..$^{15}$ Most infants with ectopic atrial tachycardia who present at $<6$ months of age will be free of tachycardia after 12 months of antiarrhythmic therapy. ${ }^{17-21}$ Simpson et al ${ }^{13}$ showed that $57 \%$ of babies who as fetuses had SVT and who survived the neonatal period required long term treatment (median duration of six months; range 1-60). For the hydropic infants, $79 \%$ of the survivors beyond the neonatal period received maintenance drugs for a median duration of 10 months (range $1-10$ ).

We tend to give full therapeutic doses until 6 months of age, and then maintain the dose until 1 year of age, when medication is stopped. The parents are advised to watch for recurrence.

\section{Refractory SVT}

Flecainide and sotolol have a proven effect on refractory SVT as single agents and with other antiarrhythmic agents in children and adults. ${ }^{22-28}$ There must be concern about the proarrhythmic potential of these drugs in combination, but Price et $a^{29}$ found the combination of the two drugs to be safe and effective in refractory SVT in infants. It is important to note that flecainide solution currently has to be made up each week by the pharmacy. It precipitates in the cold, which can lead to dangerous overdosing, and therefore must not be refrigerated. Furthermore, milk interferes with absorption of flecainide, and thus a high serum concentration of flecainide
Summary of important dos and don'ts for antiarrhythmic medication

- DO monitor flecainide and digoxin concentrations

- DO NOT use $\beta$ blocker with calcium channel blocker

- DO NOT use intravenous verapamil below 1 year of age

- DO monitor QT intervals with sotalol

- DO halve the dose of digoxin when given with amiodarone

can develop when milk feeds are stopped-for example, during diarrhoeal illness. ${ }^{30}$

Radiofrequency ablation can be performed in infants less than 18 months old. ${ }^{31}$ It is usually reserved for drug resistant or life threatening arrhythmias, often in the presence of structural heart disease. The most common associated congenital heart diseases subjected to this procedure are Ebstein's malformation of tricuspid valve, single ventricle/ corrected transposition of the great arteries complex, tetralogy of Fallot, and hypertrophic cardiomyopathy.

\section{Fetal tachycardias and management of the hydropic infant}

Persistent or recurrent SVT usually in the form of an accessory pathway mediated tachycardia or atrial flutter can lead to hydrops or fetal death. Simpson et al ${ }^{13}$ showed that $65 \%$ of the tachycardias in the fetus were persistent and that the incidence of hydrops was $41 \%$. The incidence of congenital heart defects was $4 \%$ in the same study and $12 \%$ in another study by Boldt et al. ${ }^{12}$ Of the defects, a ventricular septal defect was the most common.

Echocardiography allows these tachycardias to be characterised, and in most cases the tachycardias can be suppressed successfully using antiarrhythmic drugs given to the mother. The figures obtained from two studies have shown a prenatal control of up to $92 \%$ of non-hydropic fetuses compared with $63 \%$ of hydropic fetuses. ${ }^{12}{ }^{13}$

If a drug cannot control the tachycardia, then premature delivery is often considered. The balance of risks in managing a hydropic infant with respiratory distress and tachycardia versus a hydropic fetus can be very difficult to assess and requires multidisciplinary input.

If a hydropic infant is delivered, there are some important principles in management.

(1) Adequate respiratory and circulatory support takes immediate precedence after delivery.

(2) Cardioversion should occur as soon as possible with adenosine or direct current.

(3) In choosing maintenance therapy or if cardioversion fails, there needs to be an awareness of which drugs were given antenatally to avoid drug toxicity and to be aware of interactions. Flecainide and digoxin are particularly arrythmogenic, and the therapeutic range is relatively narrow. It may be safer to use an alternative drug, particularly amiodarone, until serum concentrations of drugs given antenatally are known.

(4) Negative inotropes, in particular calcium channel blockers and $\beta$ blockers, are to be avoided and must not be given intravenously.

A final and important message is to document all arrhythmias with a 12 lead ECG, and have a rhythm strip running during any form of cardioversion. Expert advice is never far away, but without the evidence, even the experts will struggle. 
Authors' affiliations

D S Kothari, J R Skinner, Starship and Green Lane Hospitals, Auckland, New Zealand

Competing interests: none declared

\section{REFERENCES}

1 Sreeram N, Wren C. Supraventricular tachycardia in infants: response to initial treatment. Arch Dis Child 1990;65:127-9.

2 Rhodes LA, Walsh EP, Saul JP. Conversion of atrial flutter in paediatric patients by transesophageal atrial pacing: a safe, effective, minimally invasive procedure. Am Heart J 1995; 130:323-7.

3 Peng CC, Chen MR, Hou CJ, et al. Atrial flutter in the neonate and early infancy. Jpn Heart J 1998;39:287-95.

4 Pagis B, Villain E, Hidden-Lucet F, Frank R, Sidi D. Wolff-Parkinson-White syndrome in the child. A case report with associated atrial fibrillation. Arch Pediatr 2003;10:38-41.

5 Szumowski L, Walczak F, Urbanek P, et al. Risk factors of atrial fibrillation in patients with Wolff-Parkinson-White syndrome. Kardiol Pol 2004;60:206-16.

6 Skinner JR, Chung S-K, Montgomery D, et al. Near-miss SIDS due to Brugada syndrome. Arch Dis Child 2005;90:528-9.

7 Perry JC. Ventricular tachycardia in neonates. Pacing Clin Electrophysiol 1997;20:2061-4.

8 Walsh EP. Clinical approach to diagnosis and acute management of tachycardias in children. In: Walsh EP, Saul JP, Triedman JK, eds. Cardiac arrhythmias in children and young adults with congenital heart disease. Philadelphia: Lippincott Williams and Williams, 2001:103-4.

9 Dixon J, Foster K, Wyllie J, et al. Guidelines and adenosine dosing in supraventricular tachycardia. Arch Dis Child 2005;90:1190-1.

10 Van Engelen AD, Weijtens O, Brenner Jl, et al. Management, outcome and follow up of fetal tachycardia. J Am Coll Cardiol 1994;24:1371-5.

11 Benson DW, Dunnigan A, Bendit DG. Follow up evaluation of infan paroxysmal atrial tachycardia: transesophageal study. Circulation 1987:75:542-9.

12 Boldt T, Eronen M, Andersson S. Long term outcome in fetuses with cardiac arrhythmias. Obstet Gynecol 2003;102:1372-9.

13 Simpson JM, Yates RW, Sharland GK. Irregular heart rate in the fetus: not always benign. Cardiol Young 1996:6:28-31.

14 Ito S, Gow R, Verjee Z, et al. Intravenous and oral propafenone for treatment of tachycardia in infants and children: pharmacokinetics and clinical response. J Clin Pharmacol 1998;38:496-501.
15 Perry JC, Garson A. Supraventricular tachycardia due to Wolff-ParkinsonWhite syndrome in children: early disappearance and late recurrence. J Am Coll Cardiol 1991;16:1215-20.

16 Deal BJ, Keane JF Gillette PC Garson A. Wolff-Parkinson-White syndrome and supraventricular tachycardia during infancy: management and follow-up. J Am Coll Cardiol 1985;5:130-5.

17 Mehta AV, Sanchez GR, Sacks EJ, et al. Ectopic automatic atrial tachycardia in children: clinical characteristics, management and follow-up. J Am Coll Cardiol 1988;11:379-85.

18 Gillette PC, Garson A. Electrophysiologic and pharmacologic characteristics of automatic atrial tachycardia. Circulation 1977;56:571-5.

19 Klersy C, Chimienta M, Marangoni E, et al. Factors that predict spontaneous remission of ectopic atrial tachycardia. Eur Heart J 1993;14:1654-6.

20 Baursfeld U, Gow RM. Hamilton RM, et al. Treatment of atrial ectopic tachycardia in infants less than 6 months old. Am Heart J 1995; 129:1 145-8.

21 Naheed ZJ, Strasburger JF, Benson DW, et al. Natural history and management strategies of automatic atrial tachycardia in children. Am Heart J 1995;75:405-7.

22 Perry JC, McQuinn RL, Smith RT Jr, et al. Flecainide acetate for resistant arrhythmias in the young: efficacy and pharmacokinetics. J Am Coll Cardiol 1989;14:185-91.

23 Till JA, Shinebourne EA, Rowland E, et al. Pediatric use of flecainide in SVT: clinical efficacy and pharmacokinetics. Br Heart J 1989;62:133-9.

24 Tipple M, Sander G. Efficacy and safety of oral Sotolol in early infancy. Pacing Clin Electrophysiol 1991; 14:2062-5.

25 Tanel RE, Walsh EP, Lulu JA, et al. Sotolol for refractory arrhythmias in pediatric and young patients: initial efficacy and long term outcome. Am Heart J 1995;130:791-7.

26 Perry JC, Garson A. Flecainide acetate for treatment of tachyarrhythmias in children: review of world literature on efficacy, safety and dosing. Am Heart $J$ 1992;124:1614-21.

27 Fenrich AL, Perry JC, Friedman RA. Flecainide and amiodarone: combine therapy for refractory tachyarrhythmias in infancy. J Am Coll Cardiol 1995;25:1195-8.

28 Gossinger HD, Siostrzonek P, Mosslacher H. Combine sotolol and flecainide given at low dosage in patients with WPW syndrome. Int J Cardiol 1990;26:380-2.

29 Price JF, Kertesz NJ, Snyder CS, et al. Flecainide and sotolol: A new combination therapy for supraventricular tachycardia in children $<1$ year of age. J Am Coll Cardiol 2002;39:517-20.

30 Russell GA, Martin RP. Flecainide toxicity. Arch Dis Child 1989:64:860-2.

31 Blaufox AD, Felix GL, Saul JP, participating members of the Pediatric catheter ablation registry. RF catheter ablation in infants $\leqslant 18$ months old. Circulation $2001 ; 104: 2803-8$ 